\title{
Mathematical Modeling for the Design and Scale-Up of a Large Industrial Aerosol-Assisted Chemical Vapor Deposition Process under Uncertainty
}

\author{
Pedro I. O. Filho, Claire J. Carmalt, Panagiota Angeli, and Eric S. Fraga*
}

Cite This: https://dx.doi.org/10.1021/acs.iecr.9b05869

Read Online

ABSTRACT: Aerosol-assisted chemical vapor deposition (AACVD) can be used to produce coatings and thin films such as transparent conducting oxide (TCO) films, which are used in self-cleaning surfaces, solar cells, and other electronic and optoelectronic applications. A process based on AACVD consists of a number of steps: aerosol generation, aerosol transport, aerosol delivery, and chemical deposition. Predicting the behavior of such a process at an industrial scale is challenging due to a number of factors: the aerosol generation creates droplets of different sizes, losses are incurred in the transport, the delivery must evaporate the solvent to release the precursors, and the reactions on the surface of the deposition target may be complex. This paper describes a full process model, including the prediction of the size distribution of the generated aerosol, the number and size of droplets

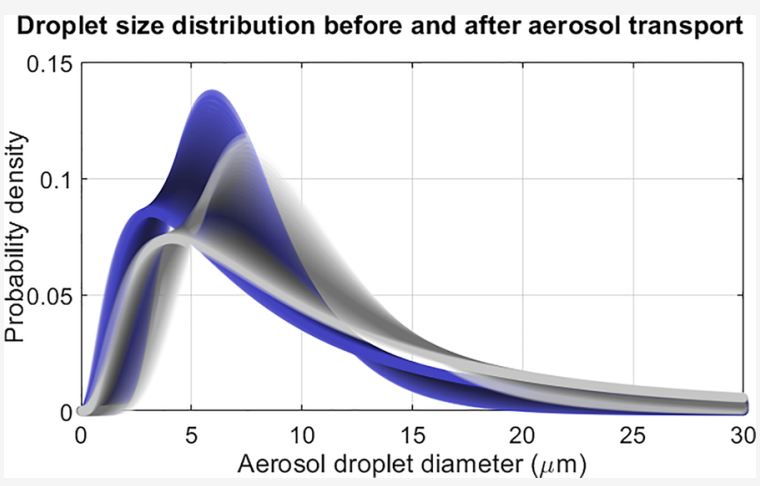
delivered, the carrier gas temperature profile at the reaction site, the solvent evaporation time, and the rate of film formation. The key modeling challenges addressed include incorporating the impact of uncertainties in parameters such as heat and mass transfer coefficients and reaction rate constants. Preliminary simulations demonstrate a proof of concept for the use of simulation for gaining insights into the feasibility of a process scale-up for an industrial-scale AACVD.

\section{INTRODUCTION}

The design of an industrial process or the improvement of an existing one has different stages to be analyzed. Uncertain parameters may be present throughout, from the synthesis, design, planning, and scheduling through to the control of processes, where unexpected variations may occur in some parameters. Not taking into account uncertainties may lead to a suboptimal operation or even failure of the process. A process for manufacturing functional thin films, for example, has reaction rate constants and transfer coefficients that may not be known or cannot be specified with certainty, leading to uncertain deposition rates. Such a process is ideally built after comparing many proposed design options, which must account for the uncertainties. Therefore, simulating the process and considering uncertainties at the design stage is essential.

Aerosol-assisted chemical vapor deposition (AACVD) is an alternative to the conventional atmospheric pressure chemical vapor deposition (CVD) process for the production of functional thin films. In either case, chemical precursors react and/or decompose on a substrate, forming the desired product. Both CVD and AACVD can be used in the synthesis of films, coatings, powders, composites, and nanotubes. ${ }^{1-5}$ Each one of these products has a particular application, as for example, in electronics and optoelectronic applications, ${ }^{6-10}$ self-cleaning surfaces, ${ }^{11-14}$ and transparent conducting oxide
(TCO) films; the last are a special class of glass coating that can be used in solar cells. ${ }^{15-18}$

CVD is based on the vaporization of the precursors before delivering them to the reaction site, while AACVD generates an aerosol from a solution containing the precursors. The advantage of AACVD is that the precursors need not be volatile, which means that a wide range of safe, easy to handle, nonvolatile precursors can be used. The aerosol-assisted method allows for easy doping since the stoichiometric ratio of dopant precursors to film precursors in the solution can be closely related to the stoichiometric ratio in the resultant film. On the contrary, conventional CVD would require precise control over gas flow rates, which can be unreliable. There are also cost benefits when using AACVD since it is no longer necessary to heat and vaporize the precursors and to heat the piping system to prevent condensation during the transport of the vaporized precursors, as is done for the conventional CVD. The morphology of the films deposited via AACVD can also be controlled as a function of the solvent used for the precursor

Received: October 23, 2019

Revised: December 28, 2019

Accepted: January 6, 2020

Published: January 6, 2020 


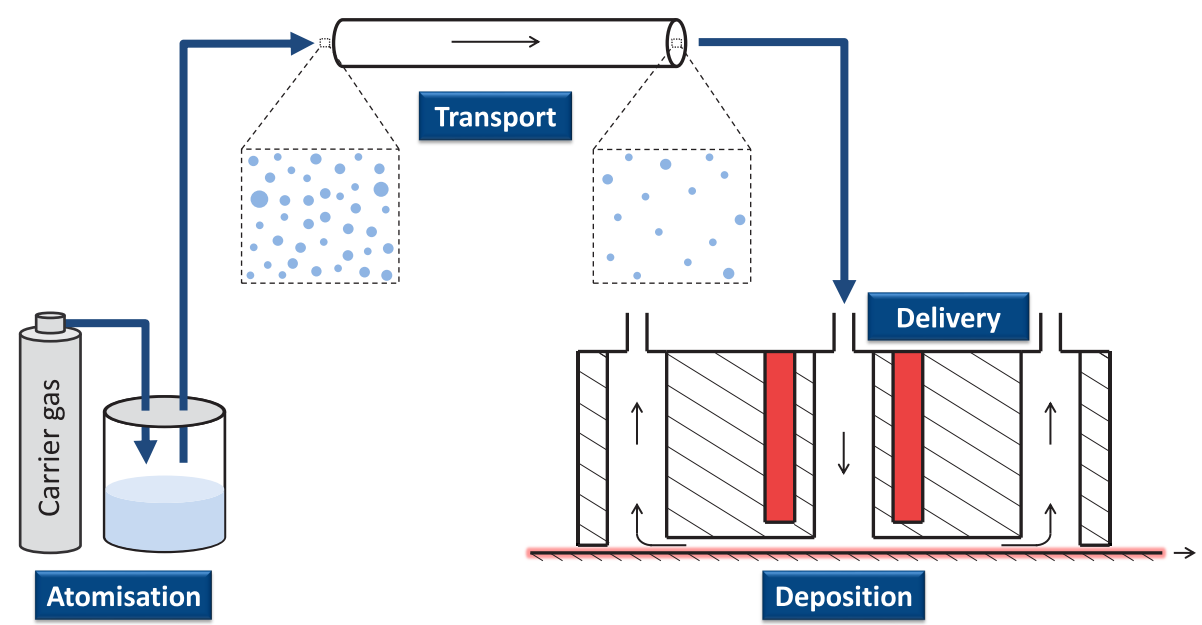

Figure 1. Schematic diagram of a large continuous industrial-scale aerosol-assisted chemical vapor deposition (AACVD) process, divided into four units: First, a solution containing the precursors is atomized via ultrasonic vibration to generate aerosol. Carrier gas is then used to transport the aerosol over long distances (tens to hundreds of meters), which causes some aerosol loss and a change of its size distribution. In the delivery unit, a cross-section of the equipment is shown, where the filled rectangles represent heat exchangers used to heat the carrier gas and evaporate the solvent, releasing the precursors. Finally, a functional thin film is continuously grown on top of a moving glass by the chemical deposition of the precursors.

solution, and different morphologies will lead to different properties, customized according to the final application. Lastly, AACVD does not need a sophisticated reactor since it can operate in an open atmosphere. ${ }^{1,2,19}$

In the lab scale, AACVD has been shown to produce lowcost, high-efficiency, and high-quality products with optical and electrical properties comparable to those of industry standards. ${ }^{1,20-32}$ The challenge is to predict the behavior of an AACVD process at the industrial scale. With that aim, we use mathematical models along with the experimental data from the successful lab-scale AACVD implementations. The success of the large-scale process can be specified in terms of the highest specific product formation rate obtained that meets the industry standard properties for the products. The scale-up procedure of the AACVD process involves assigning values for design variables that will impact the aerosol drop size distribution, the loss of aerosol during transport, the solvent evaporation, and the chemistry in the deposition site. Finally, as an alternative to designing a new plant, the AACVD process could potentially be suited to being incorporated into current CVD industrial plants for thin film deposition. We therefore look at the feasibility of generating an aerosol and transporting it to the processing line using existing CVD facilities. Challenges are mainly due to the distributed nature of drop sizes in the aerosol, the prediction of losses over long distances, the need to model the evaporation of the solvent in the delivery, and the complex reactions potentially taking place in the deposition site. We present an integrated model of the AACVD process for use in an industrial-scale design. The model is composed of the following subprocesses: aerosol generation, aerosol transport, aerosol delivery, and the chemical deposition itself, as shown and described in Figure 1.

We propose stochastic models for the prediction of the aerosol droplet size distribution and the amount delivered via piping systems. Probability density functions are used to describe the droplet sizes before and after a transport system. The temperature profile of the reaction site is modeled, as well as the solvent evaporation and the release of precursors. Finally, the chemical deposition is modeled to describe the film growth. We aim at keeping the models simple, using lumped parameters when possible to reduce the computational requirements and make them suitable for use in a future model-based design procedure. The models are also used to understand the sensitivity of the design variables to the scale of the process and, subsequently, to investigate the robustness of the design to the impact of uncertainties.

The rest of this paper is organized as follows. Section 2 presents the main considerations and challenges regarding the process scale-up, including the methodology used to perform simulations with process uncertainties. Section 3 summarizes the mathematical models used and Section 4 discusses the results from the process simulations. Finally, Section 5 draws conclusions on the feasibility of an industrial-scale AACVD process.

\section{PROCESS SCALE-UP}

Taking a process from a lab scale to an industrial scale poses significant challenges. Many variables are scale-dependent; for example, the transfer of heat is strongly dependent on the ratio of surface area to volume. Laboratory experiments are key for understanding the underlying process behavior, including reaction mechanisms and transport phenomena. However, the design of equipment at a larger scale and the criteria that may be used in making decisions about such equipment are based on the modeling of the process features. ${ }^{33,34}$ Extrapolating from the experimental parameters to obtain the industrial-scale parameters is an additional challenge since it can introduce uncertainties in the prediction of the process behavior.

Some variables will need to have their values adjusted when moving from the lab to the industrial scale. We propose models aimed at simulating the AACVD process to study how those variables will have to change in order to keep the expected outcome and the feasibility of the industrial-scale process. We will use models to guide the design of the industrial-scale process, also using data gathered from small-scale experiments. The models developed may also prove useful for the analysis of existing processes based on aerosol generation, transport, and delivery and chemical deposition. ${ }^{35-38}$ 


\subsection{Process Uncertainties and Distributed Parame-}

ters. Uncertainty is ubiquitous in the process design and scaleup, given that there is always imperfect or unknown information where it is impossible to exactly describe all the parameters. ${ }^{39}$ Uncertainties in the model predictions are also introduced when some of the model parameters are fitted from experimental data, which is usually necessary when building models for a process scale-up. Assumptions also generate a number of uncertainties in the process models. Consequently, it is important to consider the possible ranges of uncertain parameters and to understand how they impact the process, as well as ensuring that the process continues working regardless of the actual value that the parameters assume anywhere in their uncertain ranges. This grants the robustness of the process to uncertainties. Sensitivity and uncertainty analysis ${ }^{40}$ can be used to evaluate the robustness of the process models and to quantify the expected extent of variation in the process outcome, in addition to identifying the sources for variations in process performance. ${ }^{41,42}$

Some parameters may have a single exact value but there may be uncertainty about this value. Other parameters are described by distributed quantities due to variability or heterogeneity; an example of this in the case of the AACVD process is the size of droplets generated by ultrasonic vibration. Both cases can be mathematically represented using the same approach, namely, probability theory. ${ }^{43}$ Simulations of the AACVD models allow for the study, for example, of the impacts of ranges of transfer coefficients and kinetic constants. Probability distributions are used to describe such ranges. The strengths of this approach are exemplified by how straightforward it becomes to quantify and understand how likely different outcomes are and to visualize potential scenarios. Quantities such as the mean, variance, skewness, upper and lower quantile values, and confidence intervals are used to understand the impacts on the results of the uncertain and distributed parameters. Such information may also be represented graphically, using probability density functions and likelihood plots, which can help understand the predicted behavior of the scaled-up process.

2.2. AACVD Model-Based Scale-Up and Design Procedure. In considering the design and scale-up of an AACVD process, the objective is to achieve a specific deposition rate. This objective is a function of many design variables: the choice of the precursor and the properties of the precursor solution (density, viscosity, concentration, etc.), the properties of the aerosol generator (vibration frequency, rate of aerosol generation, etc.), the properties of the transport system (diameter of the transport pipes, properties of the carrier gas and its flow rate, etc.), and the properties of the deposition site (volume of reaction, speed of flowing glass, etc.). For the simulations, a goal seeking iterative method is used to identify the values of the design variables that achieve the desired deposition rate objective.

In a typical lab-scale AACVD, ${ }^{24,26,29}$ a precursor solution is prepared by dissolving $1-3 \mathrm{mmol}$ of a precursor in $10-30 \mathrm{~mL}$ of a solvent. Sometimes a small quantity of a dopant is also dissolved $(1-10 \mathrm{~mol} \%)$. The precursor solution is then atomized using, for example, an ultrasonic atomizer, which produces aerosol with a median droplet diameter ranging from 0.1 to $30 \mu \mathrm{m}$. The aerosol is transported over a small distance $(5-50 \mathrm{~cm})$ into the reactor, kept at a specific temperature using a carrier gas at a constant flow-rate of $0.5-2 \mathrm{~L} \cdot \mathrm{min}^{-1}$. The substrate can be a small float glass plate of $50-100 \mathrm{~cm}^{2}$, which is laid inside the reactor, where the chemical deposition takes place. The deposition process takes $10-30 \mathrm{~min}$ from the time aerosol starts being generated until the end of the chemical deposition.

The objective for an industrial-scale process might be instead to continuously deposit material on top of a glass with 3-4 $\mathrm{m}$ width, flowing at $10-15 \mathrm{~m} \cdot \mathrm{min}^{-1}$, at an atmospheric pressure, and at a fixed glass production temperature. As a comparative example, the process scale-up will take the labscale glass coating from the order of $1 \mathrm{~cm}^{2} \cdot \mathrm{min}^{-1}$ to the industrial-scale order of $10 \mathrm{~m}^{2} \cdot \mathrm{min}^{-1}$. This will substantially change the features of the process. First of all, the rates of aerosol generation and transport will change. A large-scale aerosol generation is already done, especially in the context of spray drying. ${ }^{44}$ Additionally, the aerosol transport in the industrial process has to be in the order of tens to hundreds of meters for safety reasons since the solvents used are often flammable and have to be kept far from the deposition site. The aerosol transport over large distances causes the loss of precursors in the piping system. Uncertainties in the transport model must be accounted for when estimating the rate of accumulation in the piping system, which could lead to clogging. Maintenance schedules can therefore be planned according to the range of possible accumulation rates and the analysis of different scenarios.

Once the carrier gas reaches the deposition site, the heat and mass transfer rates will be different from those of the lab scale. Therefore, the models will need to predict the temperature profile in the reactor using estimates for the heat transfer coefficients, which form a source of uncertainties given that they are obtained through empirical correlations. There are also uncertainties in the chemistry, specifically regarding the mechanisms of the reaction as well as the rates of gas and solid phase reactions, adsorption, and desorption. Finally, choosing the solvent and reactants and quantifying the residence time for reaction will depend on the model predictions and their accuracy. ${ }^{45}$

\section{AACVD PROCESS MODEL}

The AACVD process consists of four steps, as shown in Figure 1 , namely, aerosol generation, transport, and delivery and the chemical deposition. Each of these steps is described separately, but the models are integrated into a single model for use in simulating the complete process. For the sake of generality, the computation models used to simulate the process are written to independently accommodate different process specifications, which will then lead to different values for the design variables. For example, different plants will have different specifications for the distance where aerosol is generated and where the chemical deposition happens. The process can be simulated for any process specifications. Additionally, some parameters can be fixed; for example, the industrial setting will have moving glass being continuously coated at a fixed atmospheric pressure and at constant temperature.

While first-principles are used to estimate some parameters, others have to be determined from experimental data. The models are easily adaptable, which facilitates, for example, the proposition of different reaction mechanisms and the procedure for parameter fitting. Consideration must be taken regarding which variables are independent of the process scale and which ones must be adjusted. We strive for numbers that are representative of what could be expected in the real 
industrial-scale process, although the methodology we use is independent of the values adopted. Correlations for heat and mass transfer coefficients and thermophysical properties for possible precursor solutions and carrier gases were found in the literature. ${ }^{46-49}$

Given the challenges with computational tractability of complex problems, ${ }^{50,51}$ we have avoided the use of computational fluid dynamics (CFD). Instead, because of the complexity of the AACVD process, we propose a model that allows us to repeatedly run simulations for the design and scale-up of the process with a decreased computational time, running hundreds of simulations in seconds. This will also be useful for the multiple simulations necessary for optimizing the industrial process, with the appropriate ranges for the design variables.

The implementation of the models and description of the uncertain and distributed parameters uses Uncertain$t_{y} \cdot j 1,52$ a modeling framework focusing on the treatment of uncertainty. The framework was written in Julia (https:// julialang.org/), a high-level language that allows both largescale computation and flexible prototyping. Uncertain$t y \cdot j l$ includes methods and operators that allow models containing parameter uncertainties or distributed quantities to be easily written down and simulated. The models are written in a concise and natural syntax, compatible with a traditional mathematical notation. For instance, we can define a kinetic constant by following a normal distribution with mean $\mu$ and variance $\sigma^{2}$ simply by writing $k_{1} \sim \mathcal{N}\left(\mu, \sigma^{2}\right)$, and then use $k_{1}$ in the mass balances evaluations without having to compromise between speed and code readability. The models with uncertain parameters or distributed quantities can then be simulated and the framework will automatically provide their impacts on the results through the pertinent statistics.

3.1. Aerosol Generation. The first step in the process is the formation of the aerosol. There will not be a single size of drop in the aerosol generated due to the nonhomogeneous ejection of droplets from the liquid surface and also the collisions and agglomerations of droplets. ${ }^{53}$ The aerosol generated by ultrasonic vibration must therefore be described by a droplet size distribution. The log-normal distribution can describe variables obtained by the product of a sequence. When generating aerosol, there is a continuous process of fluid breakup, forming smaller droplets. The final droplet size is given by the product of a sequence of shrinking constants and each previous particle size, which is therefore well approximated by the log-normal distribution. The distribution only takes non-negative values, as it is the case for the droplet diameters. ${ }^{54}$ Yasuda et al. ${ }^{55}$ provided further evidence that the droplet diameters follow a log-normal distribution. The median droplet diameter $\overline{d_{\mathrm{d}}}[\mathrm{m}]$ and the standard deviation $s$ are enough to describe the theoretical distribution. These parameters are a function of the technique and equipment chosen for aerosol generation. For a target droplet diameter $\overline{d_{\mathrm{d}}}$ $[\mathrm{m}]$, the probability density function using the log-normal distribution is given by

$$
f\left(d_{\mathrm{d}}\left|\overline{d_{\mathrm{d}}}\right|, s\right)=\frac{1}{d_{\mathrm{d}} \cdot s \cdot \sqrt{2 \cdot \pi}} \mathrm{e}^{-\left(\log d_{\mathrm{d}}-\log \overline{d_{\mathrm{d}}}\right)^{2} /\left(2 \cdot \mathrm{s}^{2}\right)}
$$

A common method ${ }^{2}$ to generate aerosol droplets is by ultrasonic vibration, using a piezoelectric transducer. Assuming a log-normal distribution for the diameter of the aerosol droplets generated, the median diameter $\overline{d_{\mathrm{d}}}[\mathrm{m}]$ can be approximated as suggested by Lang: ${ }^{56}$

$$
\overline{d_{\mathrm{d}}}=0.34 \cdot\left(\frac{8 \cdot \pi \cdot \sigma_{\mathrm{d}}}{\rho_{\mathrm{d}} \cdot f^{2}}\right)^{1 / 3}
$$

where $\sigma_{\mathrm{d}}[\mathrm{N} \cdot \mathrm{m}]$ is the surface tension of the precursor solution, $\rho_{\mathrm{d}}\left[\mathrm{kg} \cdot \mathrm{m}^{-3}\right]$ is its density, and $f[\mathrm{~Hz}]$ is the excitation frequency of the transducer. Note that the fluid may be a liquid precursor or a solution containing a dissolved precursor, with a concentration $C_{A}^{\text {prec }}\left[\mathrm{mol} \cdot \mathrm{m}^{-3}\right]$ of a precursor $A$. Given the properties of the fluid, surface tension, and density, the median droplet diameter is an inverse function of the frequency, studied from $10 \mathrm{kHz}$ to $5.4 \mathrm{MHz}{ }^{56}$ Therefore, increasing the frequency will produce smaller droplets, which aids the evaporation of the solvent and the release of the precursor. Commercial ultrasonic atomizers are available for the production of droplets with sizes ranging from a fraction of a micrometer to hundreds of micrometers. ${ }^{57}$

3.2. Aerosol Transport. Frequently, the precursor chemicals are dissolved into flammable solvents. Since the deposition site is kept at a high temperature, the aerosol has to be generated at a safe distance. Suitable transport distances for industrial-scale processes range from tens to hundreds of meters. Therefore, a key element for the AACVD process scale-up is the transport of the aerosol from where it is generated to the deposition site. The aerosol transport system is usually made of straight tubes, possibly inclined, with a few bends. Losses during transport occur due to drop gravitational settling, turbulent diffusion, Brownian diffusion, and impaction in elbows. ${ }^{58}$ Brownian diffusion has a major impact on the loss of smaller particles; for instance, the diffusivity of $0.01 \mu \mathrm{m}$ particles is 20000 times higher than that of $10 \mu \mathrm{m}$ particles. ${ }^{59}$ On the contrary, the larger droplets are affected mainly by turbulent deposition and gravitational settling, which makes them more likely to be lost during transport when compared with smaller droplets. This exemplifies the importance of modeling the full range of droplet sizes being transported, given the different amounts of aerosol loss depending on the size of the droplets. Therefore, the transport model can be used to identify the optimum range of droplet sizes for different precursor solutions, which is then used to choose the atomizer settings. Since it is impossible to completely prevent aerosol loss during transport, it becomes necessary to perform regular maintenance in the transport system.

The amount of aerosol loss grows exponentially with the pipe length. ${ }^{60}$ Let $P_{\mathrm{T}} \equiv \frac{C_{\text {out }}}{C_{\text {in }}}$ be defined as the total penetration, a dimensionless variable describing the fraction of aerosol particles that successfully crossed a given piping system; the aerosol content in the pipe input and output are $C_{\text {in }}$ and $C_{\text {out }}$, respectively. The aerosol content can be measured, for example, by the number of aerosol droplets per unit volume. The total penetration, is obtained by the product of all the individual penetration fractions, $P_{\mathrm{T}}=\prod_{i} P_{\mathrm{S}, i} \prod_{j} P_{\mathrm{B}, j}$, where $P_{\mathrm{S}, i}$ is the penetration for each straight pipe section $i$ and $P_{\mathrm{B}, j}$ is the penetration for each bend $j$. Given a straight pipe section $i$ of length $L_{i}[\mathrm{~m}]$, the penetration $P_{\mathrm{S}, i}$ is modeled as ${ }^{58,60,61}$

$$
P_{S, i}=\mathrm{e}^{-\left(\pi \cdot d \cdot V_{\mathrm{e}, i} / Q\right) L_{i}}
$$

where $d[\mathrm{~m}]$ is the pipe diameter and $Q\left[\mathrm{~m}^{3} \cdot \mathrm{s}^{-1}\right]$ is the fluid flow rate. $V_{\mathrm{e}, i}\left[\mathrm{~m} \cdot \mathrm{s}^{-1}\right]$ is defined as the effective velocity of aerosol loss, as a function of the three main loss mechanisms: 
Brownian diffusion, turbulent diffusion, and gravitational settling. How to calculate the effective velocity is shown in the Supporting Information.

For each bend $j$, the penetration $P_{\mathrm{B}, j}$ is modeled as ${ }^{62-64}$

$$
\begin{aligned}
P_{\mathrm{B}, j}= & 1-\frac{1}{\pi \cdot r_{0}}\left[\left(\frac{(\sin \alpha)^{2} \cdot \mathrm{e}^{2 \cdot \Gamma_{\alpha}}}{\left(\eta\left(\Gamma_{\alpha}\right)\right)^{2}}-1\right) .\right. \\
& \left(z_{\alpha} \cdot\left(r_{0}{ }^{2}+1\right)-\frac{z_{\alpha}{ }^{3}}{3}\right)+r_{0} \cdot\left(\frac{(\sin \alpha)^{2} \cdot \mathrm{e}^{2 \cdot \Gamma_{\alpha}}}{\left(\eta\left(\Gamma_{\alpha}\right)\right)^{2}}+1\right) . \\
& \left.\left(z_{\alpha} \cdot \sqrt{1-z_{\alpha}^{2}}+\arcsin \left(z_{\alpha}\right)\right)\right]
\end{aligned}
$$

where $r_{0}$ is the dimensionless curvature ratio, defined as the bend radius $r_{\mathrm{b}}[\mathrm{m}]$ divided by the pipe radius $r[\mathrm{~m}]$, and $\alpha$ $[\mathrm{rad}]$ is the bend angle. The Supporting Information contains the equations to calculate $\Gamma_{\alpha}$, the dimensionless time at impact; $\eta$, a dimensionless coordinate function of the dimensionless time $\Gamma$; and $z_{\alpha}$, the $z$-axis coordinate at impact. The correlations above are based on experimental data ${ }^{58,60-64}$ and are subject to specific experimental ranges of Stokes and Reynolds numbers.

3.3. Aerosol Delivery. Once the aerosol droplets leave the transport system, which is likely to be at room temperature, they enter a region that is heated. This happens when the carrier gas travels through the middle of the distributor beam, as can be seen in Figure 1 (bottom right-hand side), where the filled rectangles represent heat exchangers. The solvent will dry out and the precursors will be released. As the carrier gas travels through the heated delivery section, its temperature will increase with time, as given by

$$
\frac{\mathrm{d}}{\mathrm{d} t} T=\frac{v_{\mathrm{g}} \cdot h_{1} \cdot P \cdot\left(T_{\mathrm{w}}-T\right)}{\dot{m} \cdot c_{p}}
$$

where $T[\mathrm{~K}]$ is the carrier gas mean temperature; $t[\mathrm{~s}]$ is time; $v_{\mathrm{g}}\left[\mathrm{m} \cdot \mathrm{s}^{-1}\right]$ is the carrier gas velocity; $h_{1}\left[\mathrm{~W} \cdot \mathrm{m}^{-2} \cdot \mathrm{K}^{-1}\right]$ is the heat transfer coefficient; $P[\mathrm{~m}]$ is the surface perimeter; $T_{\mathrm{w}}[\mathrm{K}]$ is the wall temperature; and $\dot{m}\left[\mathrm{~kg} \cdot \mathrm{s}^{-1}\right]$ and $c_{p}\left[\mathrm{~J} \cdot \mathrm{kg}^{-1} \cdot \mathrm{K}^{-1}\right]$ are, respectively, the carrier gas mass flow rate and specific heat at a constant pressure. The droplet evaporation is modeled by mass and energy balances. The process can be divided into two stages: The first one is the reduction of the droplet diameter, given the evaporation of the aerosol. For the second stage, the moisture content reaches a critical value and the solid precursors start to appear. In addition to eq 5, another two differential equations are numerically solved simultaneously: ${ }^{46,48}$

$$
\begin{aligned}
& \frac{\mathrm{d}}{\mathrm{d} t} T_{\mathrm{d}}=\frac{1}{c_{p, \mathrm{~d}} \cdot m_{\mathrm{d}}}\left(h_{2} \cdot \pi \cdot d_{\mathrm{d}}{ }^{2} \cdot\left(T-T_{\mathrm{d}}\right)-h_{\mathrm{vap}, \mathrm{d}} \cdot \dot{m}_{\mathrm{v}}\right) \\
& \frac{\mathrm{d}}{\mathrm{d} t} d_{\mathrm{d}}=-\frac{2 \cdot \dot{m}_{\mathrm{v}}}{\rho_{\mathrm{d}} \cdot \pi \cdot d_{\mathrm{d}}{ }^{2}}
\end{aligned}
$$

where $h_{\text {vap,d }}\left[\mathrm{J} \cdot \mathrm{kg}^{-1}\right]$ is the droplet specific heat of evaporation; $c_{p, \mathrm{~d}}\left[\mathrm{~J} \cdot \mathrm{kg}^{-1} \cdot \mathrm{K}^{-1}\right], m_{\mathrm{d}}[\mathrm{kg}], \rho_{\mathrm{d}}\left[\mathrm{kg} \cdot \mathrm{m}^{-3}\right], T_{\mathrm{d}}[\mathrm{K}]$, and $d_{\mathrm{d}}[\mathrm{m}]$ are, respectively, the droplet specific heat at a constant pressure, mass, density, temperature, and diameter; $t[\mathrm{~s}]$ is time; $h_{2}[\mathrm{~W}$. $\left.\mathrm{m}^{-2} \cdot \mathrm{K}^{-1}\right]$ is the heat transfer coefficient; $T[\mathrm{~K}]$ is the carrier gas mean temperature; $\dot{m}_{\mathrm{v}}\left[\mathrm{kg} \cdot \mathrm{s}^{-1}\right]$ is the mass transfer rate, given by $\dot{m}_{\mathrm{v}}=h_{\mathrm{m}, \mathrm{s}} \cdot\left(\rho_{\mathrm{v}, \mathrm{s}}-\rho_{\mathrm{v}, \infty}\right) \cdot \pi \cdot d_{\mathrm{d}}^{2}$ where $h_{\mathrm{m}, \mathrm{s}}\left[\mathrm{m} \cdot \mathrm{s}^{-1}\right]$ is the solvent mass transfer coefficient; and $\rho_{\mathrm{v}, \mathrm{s}}\left[\mathrm{kg} \cdot \mathrm{m}^{-3}\right]$ and $\rho_{\mathrm{v}, \infty}$ $\left[\mathrm{kg} \cdot \mathrm{m}^{-3}\right]$ are, respectively, the partial vapor densities over the droplet surface and far from it. The Supporting Information shows how to calculate the solvent mass transfer coefficient and the partial vapor densities, which are all functions of the droplet temperature.

3.4. Chemical Deposition. The delivery model predicts the temperature profile in the deposition site and the rate of solvent evaporation. Now, the deposition reactions occur in gas and solid phases and consist of multiple steps happening both in series and in parallel. Before obtaining the final product, there may be both detectable and undetectable intermediates and undesired reaction impurities. ${ }^{35}$ Building a robust chemical process, with a reproducible reaction performance, would require the understanding of the mechanisms and the competing rates of reactions, as well as the interplay between kinetic effects, mass transfer, and energy-related effects. Sophisticated methodologies can be used to study the mechanism and kinetics of specific reactions as, for example, Wang et al. ${ }^{65}$ did using an in situ environmental scanning electron microscopy for the production of single-layer graphene growth on platinum foils. This is a first step to build specific mathematical models to describe that reaction in particular. Many other studies have been conducted to study synthetic methodologies, mechanisms, and kinetics of deposition for different materials, as well as the correlation between properties. $^{32,66-78}$

As an alternative, we propose a general modeling methodology that requires simpler measurements, such as the film growth rate, and some idea of the mechanisms involved. The objective is to have models that are independent from the full understanding of the mechanisms for each reaction, avoiding the cost of a thorough investigation toward the phase, composition, and morphology of the deposition products. It is important to recognize that the accuracy and generality of predictions given by the simplified models are dictated by the amount of experimental data and the level of mechanistic understanding when building them. The parameters can, however, have their values improved with more experiments. With a greater knowledge on specific reactions, more sophisticated models can be used. ${ }^{79-83}$

Modeling the film formation can bring insights about the chemical mechanisms and the competition between mass transfer and reaction kinetics, which will affect the final products. Our objective is, therefore, to specifically model the lab-scale CVD batch reactor and to generalize the results to the industrial-scale process. This means we must migrate from sequential batch depositions in the lab to a continuous deposition on top of a flowing glass in the industrial setting. In both cases, when the aerosol reaches the reaction chamber, the solvent evaporates and chemical reactions take place, resulting in the film formation.

Equation 7 represents a set of general chemical reactions:

$$
\begin{aligned}
& \mathrm{A}_{(\mathrm{g})} \underset{k_{1}}{\stackrel{\text { gas }}{\rightarrow}} \mathrm{B}_{(\mathrm{g})}+\mathrm{C}_{(\mathrm{g})} \\
& \mathrm{B}_{(\mathrm{s})} \underset{k_{2}}{\stackrel{\text { surface }}{\longrightarrow}} \mathrm{C}_{(\mathrm{s})}+\mathrm{D}_{(\mathrm{s})} \\
& \mathrm{A}_{(\mathrm{s})} \underset{k_{3}}{\stackrel{\text { surface }}{\longrightarrow}} 2 \mathrm{C}_{(\mathrm{s})}+\mathrm{D}_{(\mathrm{s})}
\end{aligned}
$$

where $\mathrm{A}$ is the precursor, whose properties affects the aerosol generation, transport, and delivery; $\mathrm{B}$ is an intermediate; $\mathrm{C}$ is a 
byproduct; $\mathrm{D}$ is the main product forming the film; and $k_{i}$ [units vary] is the kinetic constant of reaction $i$, in the gas phase or on the surface. An example of a reaction following the above mechanism is the conversion of monosilane for the production of high-grade polysilicon. ${ }^{84}$ The deposition rate is affected by thermodynamic, kinetic, and mass diffusion factors, any of which may be dominant depending on the operating conditions of the reactor. ${ }^{85}$ Those factors are described in the dynamic model for the lab batch reactor, which is obtained by performing material balances:

$$
\begin{aligned}
& \frac{\mathrm{d}}{\mathrm{d} t} n_{\mathrm{A}}^{\mathrm{g}}=\dot{F}_{\mathrm{in}} \cdot C_{\mathrm{A}}^{\mathrm{in}}-\dot{F}_{\text {out }} \cdot \frac{n_{\mathrm{A}}^{\mathrm{g}}}{V}-h_{\mathrm{m}, \mathrm{A}} \cdot A \cdot\left(\frac{n_{\mathrm{A}}^{\mathrm{g}}}{V}-\frac{n_{\mathrm{A}}^{\mathrm{s}}}{V_{\text {int }}}\right)-k_{1} \cdot n_{\mathrm{A}}^{\mathrm{g}} \\
& \frac{\mathrm{d}}{\mathrm{d} t} n_{\mathrm{A}}^{\mathrm{s}}=A \cdot h_{\mathrm{m}, \mathrm{A}} \cdot\left(\frac{n_{\mathrm{A}}^{\mathrm{g}}}{V}-\frac{n_{\mathrm{A}}^{\mathrm{s}}}{V_{\text {int }}}\right)-A \cdot k_{3} \cdot \frac{n_{\mathrm{A}}^{\mathrm{s}}}{V_{\text {int }}} \\
& \frac{\mathrm{d}}{\mathrm{d} t} n_{\mathrm{B}}^{\mathrm{g}}=\dot{F}_{\text {in }} \cdot C_{\mathrm{B}}^{\text {in }}-\dot{F}_{\text {out }} \cdot \frac{n_{\mathrm{B}}^{\mathrm{g}}}{V}-h_{\mathrm{m}, \mathrm{B}} \cdot A \cdot\left(\frac{n_{\mathrm{B}}^{\mathrm{g}}}{V}-\frac{n_{\mathrm{B}}^{\mathrm{s}}}{V_{\text {int }}}\right)+k_{1} \cdot n_{\mathrm{A}}^{\mathrm{g}} \\
& \frac{\mathrm{d}}{\mathrm{d} t} n_{\mathrm{B}}^{\mathrm{s}}=A \cdot h_{\mathrm{m}, \mathrm{B}} \cdot\left(\frac{n_{\mathrm{B}}^{\mathrm{g}}}{V}-\frac{n_{\mathrm{B}}^{\mathrm{s}}}{V_{\text {int }}}\right)-A \cdot k_{2} \cdot \frac{n_{\mathrm{B}}^{\mathrm{s}}}{V_{\text {int }}} \\
& \frac{\mathrm{d}}{\mathrm{d} t} n_{\mathrm{C}}^{\mathrm{g}}=\dot{F}_{\mathrm{in}} \cdot C_{\mathrm{C}}^{\mathrm{in}}-\dot{F}_{\text {out }} \cdot \frac{n_{\mathrm{C}}^{\mathrm{g}}}{V}-h_{\mathrm{m}, \mathrm{C}} \cdot A \cdot\left(\frac{n_{\mathrm{C}}^{\mathrm{g}}}{V}-\frac{n_{\mathrm{C}}^{\mathrm{s}}}{V_{\text {int }}}\right)+k_{1} \cdot n_{\mathrm{A}}^{\mathrm{g}} \\
& \frac{\mathrm{d}}{\mathrm{d} t} n_{\mathrm{C}}^{\mathrm{s}}=A \cdot h_{\mathrm{m}, \mathrm{C}} \cdot\left(\frac{n_{\mathrm{C}}^{\mathrm{g}}}{V}-\frac{n_{\mathrm{C}}^{\mathrm{s}}}{V_{\text {int }}}\right)+A \cdot k_{2} \cdot \frac{n_{\mathrm{B}}^{\mathrm{s}}}{V_{\text {int }}}+2 \cdot A \cdot k_{3} \cdot \frac{n_{\mathrm{A}}^{\mathrm{s}}}{V_{\text {int }}} \\
& \frac{\mathrm{d}}{\mathrm{d} t} n_{\mathrm{D}}^{\mathrm{g}}=\dot{F}_{\mathrm{in}} \cdot C_{D}^{\mathrm{in}}-\dot{F}_{\text {out }} \cdot \frac{n_{\mathrm{D}}^{\mathrm{g}}}{V}-h_{\mathrm{m}, \mathrm{D}} \cdot A \cdot\left(\frac{n_{\mathrm{D}}^{\mathrm{g}}}{V}-\frac{n_{\mathrm{D}}^{\mathrm{s}}}{V_{\text {int }}}\right) \\
& \frac{\mathrm{d}}{\mathrm{d} t} n_{\mathrm{D}}^{\mathrm{s}}=A \cdot h_{\mathrm{m}, \mathrm{D}} \cdot\left(\frac{n_{\mathrm{D}}^{\mathrm{g}}}{V}-\frac{n_{\mathrm{D}}^{\mathrm{s}}}{V_{\text {int }}}\right)+A \cdot k_{2} \cdot \frac{n_{\mathrm{B}}^{\mathrm{s}}}{V_{\text {int }}}+A \cdot k_{3} \cdot \frac{n_{\mathrm{A}}^{\mathrm{s}}}{V_{\text {int }}}
\end{aligned}
$$

where component $j$ is described by its inlet feed concentration, $C_{j}^{\text {in }}\left[\mathrm{mol} \cdot \mathrm{m}^{-3}\right]$, its amount of substance in the gas phase, $n_{j}^{\mathrm{g}}$ [mol], and its amount of substance in the solid phase on top of the substrate, $n_{j}^{\mathrm{s}}[\mathrm{mol}] ; t[\mathrm{~s}]$ is the reaction time; $\dot{F}_{\text {in }}\left[\mathrm{m}^{3} \cdot \mathrm{s}^{-1}\right]$ and $\dot{F}_{\text {out }}\left[\mathrm{m}^{3} \cdot \mathrm{s}^{-1}\right]$ are, respectively, the inlet and outlet volumetric flow rates of the carrier gas; $h_{\mathrm{m}, j}\left[\mathrm{~m} \cdot \mathrm{s}^{-1}\right]$ is the gas to solid phase mass transfer coefficient of component $j ; V$ $\left[\mathrm{m}^{3}\right]$ is the gas phase reaction volume; $V_{\text {int }}\left[\mathrm{m}^{3}\right]$ is the solidgas interface volume; and $A\left[\mathrm{~m}^{2}\right]$ is the glass surface area in contact with the gas. Note that $\dot{F}_{\text {in }}=\dot{F}_{\text {out }}=Q$ when there is no accumulation, where $Q\left[\mathrm{~m}^{3} \cdot \mathrm{s}^{-1}\right]$ is the carrier gas flow rate from eq 3 . The reaction rate constants and the mass transfer coefficients are not known exactly and are then represented using probability distributions. Therefore, the solution of the ODE system will then return a distribution, which is used to predict the most likely values of the final amounts of each material.

For the industrial-scale deposition on a continuously flowing glass, the process operates at a steady state. When the batch is compared with the continuous process, the time derivatives in eq 8 become dependent on space and time, given that the carrier gas flows inside the distributor beam and on top of the moving glass, where the film grows, as shown in the bottom right-hand side of Figure 1. Since we are interested in the profile of the film growth as the glass moves, we discretized the reaction space into small parallelograms and solved eq 8 for each one of them. The flow rate of carrier gas and the speed of the flowing glass dictate the residence time of the precursors in each discretized parallelogram. The result is the film growth profile as the glass flows through the deposition zone. The final amount of deposited D, $n_{\mathrm{D}}^{\mathrm{s}}[\mathrm{mol}]$, and the film thickness, $\tau$ $[\mathrm{m}]$, will be given by

$$
\begin{aligned}
n_{\mathrm{D}}^{\mathrm{s}} & =\rho_{\mathrm{d}} \cdot \int_{d_{\mathrm{d}}} \int_{\mathrm{t}} f(\mathbf{x}) \mathrm{d} t \mathrm{~d} d_{\mathrm{d}} \\
\tau & =\frac{n_{\mathrm{D}}^{\mathrm{s}}}{\bar{\rho} \cdot w \cdot v \cdot t_{\mathrm{r}}}
\end{aligned}
$$

where $f(\mathbf{x})$ represents the integrated models for aerosol generation, transport, and delivery and chemical deposition described above; $\rho_{\mathrm{d}}\left[\mathrm{kg} \cdot \mathrm{m}^{-3}\right]$ is the density of the precursor solution; $d_{\mathrm{d}}[\mathrm{m}]$ is the droplet diameter; $t[\mathrm{~s}]$ is time; $\bar{\rho}[\mathrm{mol}$. $\left.\mathrm{m}^{-3}\right]$ is the mean molar density of the film; $w[\mathrm{~m}]$ is the glass width; $v\left[\mathrm{~m} \cdot \mathrm{s}^{-1}\right]$ is the speed of the flowing glass; and $t_{\mathrm{r}}[\mathrm{s}]$ is the chemical deposition residence time, defined as the time taken by the glass to cross the distributor beam. Note that the glass surface area in contact with the gas, $A\left[\mathrm{~m}^{2}\right]$, is given by the product $w \cdot v \cdot t_{\mathrm{r}}$.

\section{RESULTS AND DISCUSSION}

On the basis of set targets, the results will be shown for the aerosol generation and transport and then for the aerosol delivery and the film formation. The objective is to understand the whole process from the perspective of the industry, which is interested in large production rates of a specific film thickness. The set of parameters and their values used in the models can be found in Table 1 .

4.1. Aerosol Generation and Transport. Given the amount of reactants necessary for the production of a film with a specific thickness, the aerosol generation and transport system can be designed. For the aerosol generation, the models show that the most impactful variable on the aerosol sizing is the atomizer ultrasonic frequency. This is important, since the sizing has the greatest impact on the aerosol loss for a given transport geometry, followed by the carrier gas flow rate. Note that the relative range of the uncertain droplet sizes is much greater than the uncertainties in all the other variables in the transport model.

To illustrate the outputs of the transport model, the droplet distributions before and after a $50 \mathrm{~m}$ transport system are shown in Figure 2 for two different distributions of droplet sizes in the aerosol. Results show that $86 \%$ of the aerosol is expected to successfully reach the distributor beam for the aerosol with a $2 \mu \mathrm{m}$ median droplet diameter and $26 \%$ for the $10 \mu \mathrm{m}$ median droplet diameter. Note that more of the larger droplets are lost, indicating the importance of modeling the full range of possible droplet sizes, explained by the different extents of aerosol loss depending on the size of the particles. The optimum sizing range for transport can be found for each particular transport system. Additionally, the maintenance schedule is a function of the aerosol loss and can be determined by the presented models, varying according to the generated droplet sizes and the properties of the flow and the transport system.

4.2. Aerosol Delivery and Chemical Deposition. TCO functional films reported in the literature, ${ }^{23,25,28,86,87}$ which satisfy industry standards for the functional properties, have their thicknesses varying from $1 / 10$ to $8 \mu \mathrm{m}$, depending on how long the deposition process is allowed to take place. Most 
Table 1. Values Used for the Model Parameters in the Industrial-Scale Range with the Objective of Continuously Coating Glass with 425 nm Film Thickness

\begin{tabular}{|c|c|c|c|}
\hline symbol & parameter & nominal value & units \\
\hline$A$ & $\begin{array}{l}\text { glass surface area in contact with } \\
\text { the gas }\end{array}$ & $4.5 \times 10^{-3}$ & $\mathrm{~m}^{2}$ \\
\hline$c_{p, \mathrm{~d}}$ & droplet average specific heat & $2.6 \times 10^{3}$ & $\mathrm{~J} \cdot \mathrm{kg}^{-1} \cdot \mathrm{K}^{-1}$ \\
\hline$c_{p}$ & carrier gas average specific heat & $1.1 \times 10^{3}$ & $\mathrm{~J} \cdot \mathrm{kg}^{-1} \cdot \mathrm{K}^{-1}$ \\
\hline$h_{1}$ & $\begin{array}{l}\text { heat transfer coefficient wall to } \\
\text { carrier gas }\end{array}$ & 6 & $\mathrm{~W} \cdot \mathrm{m}^{-2} \cdot \mathrm{K}^{-1}$ \\
\hline$h_{2}$ & $\begin{array}{l}\text { heat transfer coefficient carrier gas } \\
\text { to droplet }\end{array}$ & $2.5 \times 10^{3}$ & $\mathrm{~W} \cdot \mathrm{m}^{-2} \cdot \mathrm{K}^{-1}$ \\
\hline$h_{\mathrm{m}, \mathrm{A}}$ & $\begin{array}{l}\text { mass transfer coefficient of } \\
\text { component } \mathrm{A}\end{array}$ & $7.4 \times 10^{-4}$ & $\mathrm{~m} \cdot \mathrm{s}^{-1}$ \\
\hline$h_{\mathrm{m}, \mathrm{B}}$ & $\begin{array}{l}\text { mass transfer coefficient of } \\
\text { component B }\end{array}$ & $1.2 \times 10^{-2}$ & $\mathrm{~m} \cdot \mathrm{s}^{-1}$ \\
\hline$h_{\mathrm{m}, \mathrm{C}}$ & $\begin{array}{l}\text { mass transfer coefficient of } \\
\text { component } C\end{array}$ & $1.4 \times 10^{-3}$ & $\mathrm{~m} \cdot \mathrm{s}^{-1}$ \\
\hline$h_{\mathrm{m}, \mathrm{D}}$ & $\begin{array}{l}\text { mass transfer coefficient of } \\
\text { component } \mathrm{D}\end{array}$ & $1 \times 10^{-9}$ & $\mathrm{~m} \cdot \mathrm{s}^{-1}$ \\
\hline$h_{\mathrm{m}, \mathrm{s}}$ & $\begin{array}{l}\text { mass transfer of the precursor } \\
\text { solvent }\end{array}$ & 1.5 & $\mathrm{~m} \cdot \mathrm{s}^{-1}$ \\
\hline$h_{\text {vap }, d}$ & droplet specific heat of evaporation & $1.2 \times 10^{6}$ & $\mathrm{~J} \cdot \mathrm{kg}^{-1}$ \\
\hline$k_{1}$ & kinetic constant of reaction 1 & 1.62 & $\mathrm{~s}^{-1}$ \\
\hline$k_{2}$ & kinetic constant of reaction 2 & $8.96 \times 10^{-4}$ & $\mathrm{~m} \cdot \mathrm{s}^{-1}$ \\
\hline$k_{3}$ & kinetic constant of reaction 3 & $5.6 \times 10^{-4}$ & $\mathrm{~m} \cdot \mathrm{s}^{-1}$ \\
\hline$L$ & transport system distance & $5.0 \times 10^{1}$ & $\mathrm{~m}$ \\
\hline$N$ & number of $90^{\circ}$ pipe bends & 5 & \\
\hline$P$ & $\begin{array}{l}\text { contact surface perimeter for heat } \\
\text { transfer in the distributor beam }\end{array}$ & 6.4 & $\mathrm{~m}$ \\
\hline$s$ & $\begin{array}{l}\text { standard deviation for the droplet } \\
\text { log-normal distribution }\end{array}$ & 0.6 & \\
\hline$T_{\mathrm{w}}$ & wall temperature & $7.8 \times 10^{2}$ & $\mathrm{~K}$ \\
\hline$v_{\mathrm{g}}$ & $\begin{array}{l}\text { carrier gas velocity inside the } \\
\text { deposition beam }\end{array}$ & 0.3 & $\mathrm{~m} \cdot \mathrm{s}^{-1}$ \\
\hline$V$ & reactor volume & $1.4 \times 10^{-4}$ & $\mathrm{~m}^{3}$ \\
\hline$V_{\text {int }}$ & solid-gas interface volume & $1 \times 10^{-5}$ & $\mathrm{~m}^{3}$ \\
\hline$\mu$ & carrier gas dynamic viscosity & $5.5 \times 10^{-4}$ & $\mathrm{~N} \cdot \mathrm{s} \cdot \mathrm{m}^{-2}$ \\
\hline$\mu_{\mathrm{d}}$ & droplet dynamic viscosity & $1.9 \times 10^{-5}$ & $\mathrm{~N} \cdot \mathrm{s} \cdot \mathrm{m}^{-2}$ \\
\hline$\rho$ & carrier gas density & 1.2 & $\mathrm{~kg} \cdot \mathrm{m}^{-3}$ \\
\hline $\bar{\rho}$ & film average molar density & $7 \times 10^{4}$ & $\mathrm{~mol} \cdot \mathrm{m}^{-3}$ \\
\hline$\rho_{\mathrm{d}}$ & droplet density & $7.9 \times 10^{2}$ & $\mathrm{~kg} \cdot \mathrm{m}^{-3}$ \\
\hline$\sigma_{\mathrm{d}}$ & droplet surface tension & $2.2 \times 10^{-2}$ & $\mathrm{~N} \cdot \mathrm{m}^{-1}$ \\
\hline$\Phi$ & $\begin{array}{l}\text { volume fraction of aerosol in the } \\
\text { carrier gas }\end{array}$ & 0.02 & \\
\hline symbol & design variable & range & units \\
\hline$C_{\mathrm{A}}^{\text {prec }}$ & $\begin{array}{l}\text { concentration of precursor } \mathrm{A} \text { in } \\
\text { the solution to generate aerosol }\end{array}$ & {$[0.01,1.0] \times 10^{3}$} & $\mathrm{~mol} \cdot \mathrm{m}^{-3}$ \\
\hline$d$ & pipe inner diameter & {$[0.5,9] \times 10^{-2}$} & $\mathrm{~m}$ \\
\hline$f$ & atomizer ultrasonic frequency & {$[0.1,54] \times 10^{5}$} & $\mathrm{~Hz}$ \\
\hline$\dot{F}_{\text {in }}$ & carrier gas volumetric flow rate & {$[1,7] \times 10^{-2}$} & $\mathrm{~m}^{3} \cdot \mathrm{s}^{-1}$ \\
\hline$N_{\mathrm{P}}$ & number of parallel pipes & {$[1,10]$} & \\
\hline
\end{tabular}

papers published showing experimental work only report values of the final film thickness for a given reaction residence time. These values allow us, as a first approximation, to quantify the uncertain coefficients in systems of ODEs analogous to the one represented in eq 8 . We can also estimate the conversion fraction of precursors on the basis of the final film thickness and the initial quantity of precursors used. Our objective is simulating the continuous industrialscale AACVD process; therefore, lab-scale batch experiments are used to study the reaction kinetics and transfer coefficients, which will then inform the models for the large-scale simulations. Equation 8 will have its scale-dependent parameters adjusted according to the scale, having different

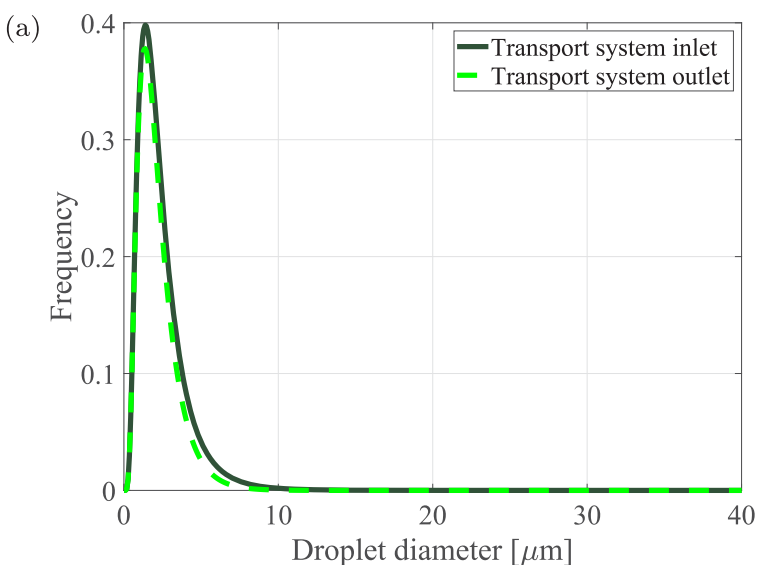

(b)

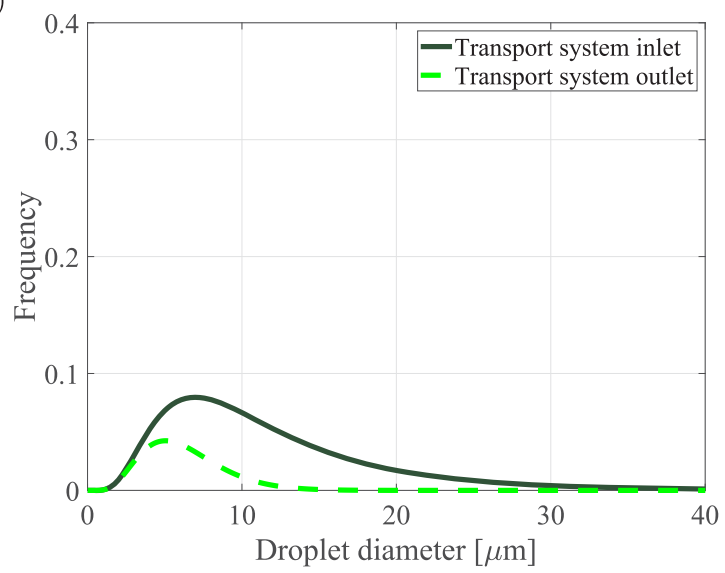

Figure 2. Droplet diameter distribution before and after a $50 \mathrm{~m}$ transport system. Inlet median droplet diameter $2 \mu \mathrm{m}$ for (a) and 10 $\mu \mathrm{m}$ for (b). The area under the inlet curve is unitary, while the area under the outlet curve is the fraction of aerosol expected in the outlet of the transport system, 0.86 for (a) and 0.26 for (b).

contact surface areas, flow rates, and concentrations. On the contrary, the mass transfer coefficients and kinetic constants are scale-independent and are estimated using the experiments.

The parameter estimation procedure from the experimental data emphasizes the need to handle uncertainties that arise from the scale-up. For example, by using the final film thickness and deposition time from a lab-scale batch experiment, the scale-independent parameters are fitted and their predicted time behavior can be seen in Figure 3a. The time starts being counted when the reactant starts being delivered to the deposition site. The film starts growing at an approximately constant rate after $1 \mathrm{~min}$, and analogous experiments usually last for about $15 \mathrm{~min}$. Note that Figure 3a shows the most likely results. However, due to the uncertainties in the model parameters, there is actually a distribution of possible results for each time interval. As an example, Figure $3 \mathrm{~b}$ shows the likelihood plot of the amounts of reactant $\mathrm{A}$ and main product $\mathrm{D}$, specifically for time $t=2 \mathrm{~min}$. To make the models more robust, it would be necessary to collect data on the evolution of the film thickness with time. Going further, it would also be useful to measure the concentrations of reactants, intermediates, products, and byproducts.

4.3. Distributor Beam and Industrial Continuous Process. The industrial deposition site is found at the final stage of the glass production. The current plants using the 
(a)

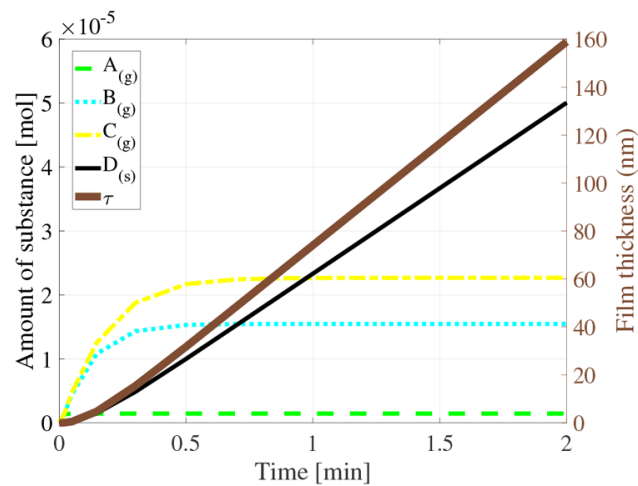

(b)

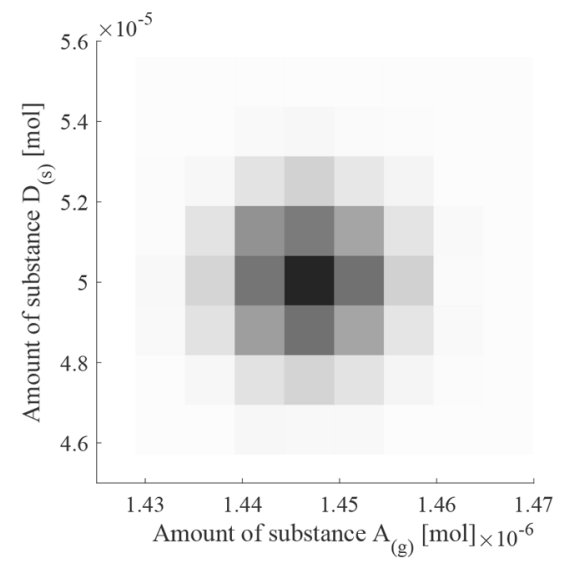

Figure 3. (a) Simulation of the lab-scale batch chemical deposition. The reactant $\mathrm{A}$ is fed at constant flow rate, component $\mathrm{B}$ is an intermediate, $\mathrm{C}$ is a byproduct, and $\mathrm{D}$ forms the thin film with thickness $\tau$ [nm] growing, as shown in the right-hand side axis. (b) Plot showing the likelihood regions for the components $\mathrm{A}$ and $\mathrm{D}$ at time $t=2 \mathrm{~min}$, given the uncertainties in the model parameters. The darker the region, the more likely it is to represent reality.

conventional CVD process use a distributor beam to deliver gaseous chemical precursors to the glass surface. Ideally, the same setting could be kept after switching to the AACVD process. In the latter case, an inert gas will carry the aerosol containing precursors to the deposition site, which is shown in the bottom right-hand side of Figure 1. The schematic diagram is similar to the distributor beam made public by the International Patent 96/11802. ${ }^{88}$ The diagram shows a crosssection of the device, where the aerosol arrives from the topmiddle part and reaches the surface of a moving glass in the $x$ axis direction on the bottom part. The formation of a thin film with specific optoelectronic properties on the glass is the final objective. The filled rectangles in the diagram are heat exchangers, which allow the temperature of the deposition site walls to be controlled.

The industrial process operates at a constant temperature and atmospheric pressure. The glass width is in the direction perpendicular to the $x y$-plane, while the vertical direction represents the distributor's height, which is adjustable and can be taken as a design variable. The carrier gas arrives at the distributor beam at room temperature and its temperature increases while traveling between the walls of the distributor beam, as modeled by eq 5 . Discretizing the $x$-axis, it is possible to solve the system of ODEs represented in eq 8 for different positions, which allows us to predict the concentration of the chemical species for different values of distance from the center of the distributor beam. It is then possible to study different variations of the patented device, as shown in Figure 4.

As the results suggest, the film growth rate is not uniform throughout the reaction space. Whether the highest growth rate happens when the film has just started forming (parallel flow setting) or when the film already has some thickness (counter flow setting) will impact the properties of the film, given that its morphology can potentially differ. The best design will depend on the chemistry for the chosen precursors to produce a specific film. Note that the results shown in Figure $4 \mathrm{e}$ are not symmetric, since that would only happen if the flow were evenly distributed to both directions. The use of the amount of substance instead of the concentration is convenient, since it allows for the representation of solid and vapor substances in the same plot. However, the concentrations of the substances in the vapor state are easily obtained and are directly proportional to their amounts; for example, Figure 5 shows the equivalent results of Figure $4 \mathrm{~b}$.

4.4. Integration of Process Units. The simulations are carried out for the different parts of the process: aerosol generation, transport, and delivery and the chemical deposition. Since the final objective of the integrated process is to meet a specific deposition rate, all variables will be dependent on the chemical deposition results. Therefore, the design of each subprocess is done on the basis of defined targets, leading to a goal seeking iterative method. For example, aiming at a final film thickness, simulations are done to evaluate each subprocess. The models presented can also be used to predict the properties of the complete industrial-scale AACVD, given the final objective of continuously coating glass flowing at a specific speed. Simulating the process before scaling-up is also important to identify possible bottlenecks in the process and to determine where to dedicate more effort and resources. It also aids in the evaluation of different process options and in the determination of process constraints, limiting factors, and feasible conditions.

We illustrate the use of the models to suggest a possible configuration for the design of an industrial-scale AACVD process, including the maintenance schedule for the aerosol transport system. The final objective is producing films with a thickness of at least $425 \mathrm{~nm}$ in a continuous industrial-scale process. The lab-scale experimental results shown in section 4.2 are used to fit the mass transfer coefficients and kinetic constants from eq 8 for the deposition site, which are scaleindependent when using the same components and reactions. We then estimate the necessary flow rate of precursors arriving at the reaction site. Results show that a film of $425 \mathrm{~nm}$ thickness is obtained when using a total flow rate of $0.03 \mathrm{~m}^{3}$. $\mathrm{s}^{-1}$, with reactant concentration of $10 \mathrm{~mol} \cdot \mathrm{m}^{-3}$, and divided into five parallel pipes of $6.2 \mathrm{~cm}$ inner diameter. A high conversion of reactants of $88 \%$ is obtained; however, only $7 \%$ of what reacted is converted into the main product $D$, the remainder becoming unreacted intermediate $\mathrm{B}$ and byproduct C. These results are shown in Figure $4 \mathrm{f}$ for the industrial deposition site shown in Figure 4e. The aerosol transport and delivery models show that for the $10 \mathrm{~mol} \cdot \mathrm{m}^{-3}$ concentration in the reactor, the concentration in the beginning of the transport system must be $11.6 \mathrm{~mol} \cdot \mathrm{m}^{-3}$, since about $14 \%$ of the aerosol will be lost over a $50 \mathrm{~m}$ transport distance for $2 \mu \mathrm{m}$ median droplet diameter (atomizer frequency $1.8 \mathrm{MHz}$ ), as shown in Figure 2a. For this droplet distribution, the solvent will fully evaporate before the reactants reach the glass. If the aerosol volume fraction in the carrier gas is $2 \%$, the precursor solution 
(a)

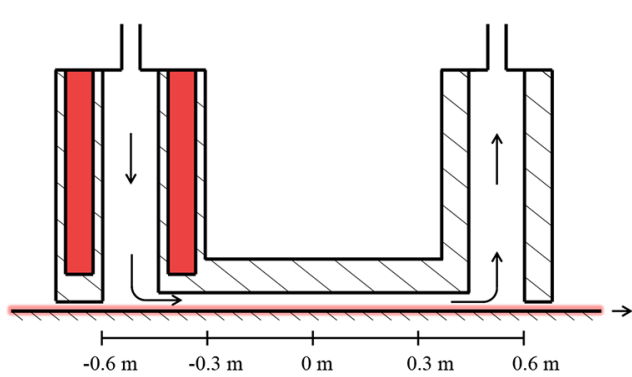

(c)

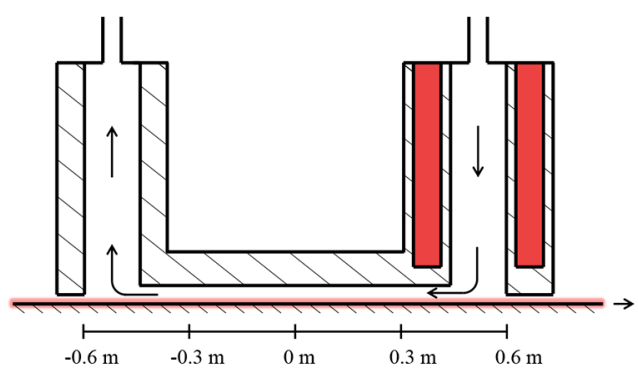

(e)

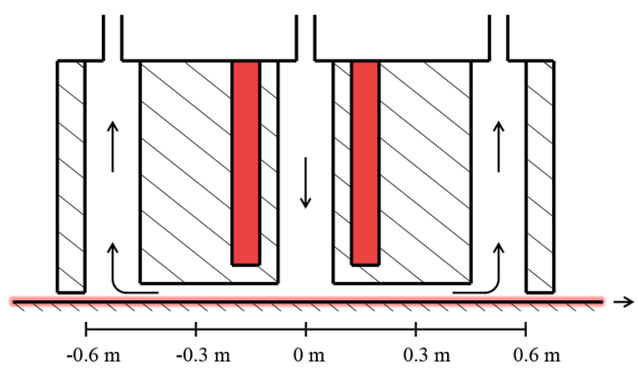

(b)

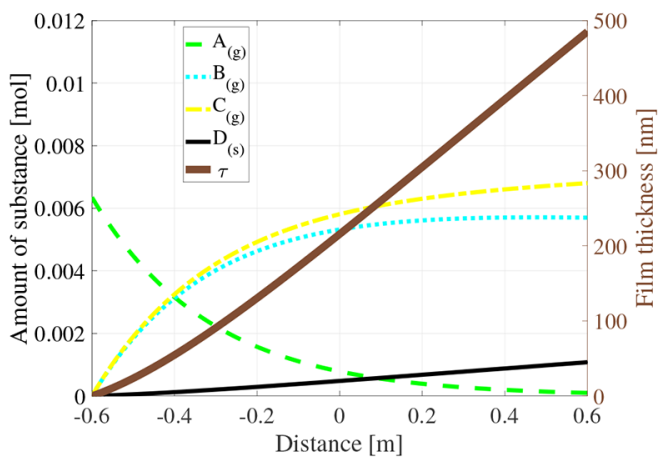

(d)

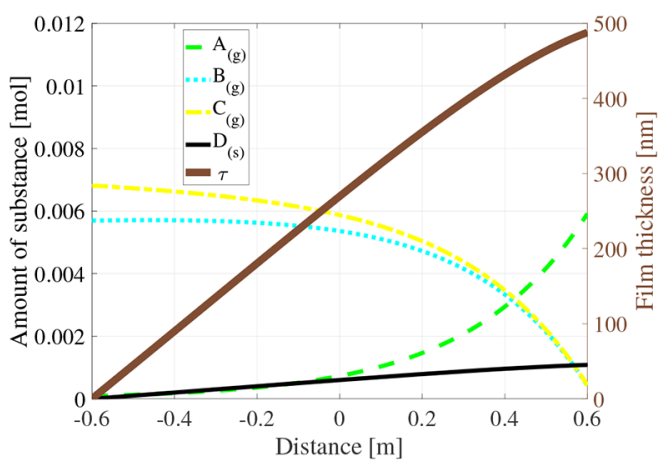

(f)

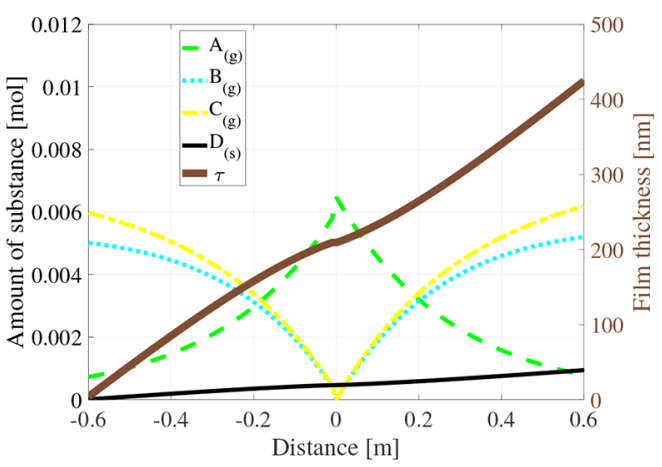

Figure 4. In the first column, schematic diagrams represent the cross-section of the deposition site in the direction of the glass, flowing from left to right. Each schematic has its respective chemical deposition simulation results, shown in the second column. The parallel flow setting is shown in (a) and (b), the counter flow setting is shown in (c) and (d) and the mixed flow setting is shown in (e) and (f). The reactant A is consumed, while intermediate $\mathrm{B}$ and byproduct $\mathrm{C}$ are produced and the film is formed by component $\mathrm{D}$. The film thickness, $\tau$ [nm], is shown in the secondary axis.

used for the aerosol generation must therefore have a concentration of $580 \mathrm{~mol} \cdot \mathrm{m}^{-3}$.

Given that $14 \%$ of aerosol is lost during transport and assuming that the transport system must always have $99 \%$ of the piping system unclogged for uniform loss throughout the piping system and an average lost material density of $5 \times 10^{4}$ $\mathrm{mol} \cdot \mathrm{m}^{-3}$, it would be necessary to run a solvent through the pipe system to clean it every $227 \mathrm{~h}$ of plant operation. To highlight the impact of the range of droplet sizes, if an aerosol with a $10 \mu \mathrm{m}$ median droplet diameter (atomizer frequency $170 \mathrm{kHz}$ ) were used instead of $2 \mu \mathrm{m}$, the aerosol loss would jump from 14 to $74 \%$, as shown in Figure $2 \mathrm{~b}$. By the same flow rate and precursor concentration being kept, the film produced would have its thickness dropping from 425 to $110 \mathrm{~nm}$ and the transport system would have to be cleaned every $12 \mathrm{~h}$ of plant operation. Increasing the precursor solution concentration and/or increasing the flow rate would increase the film thickness. This is an iterative process, since the changes in the concentration and/or flow rate will change the properties of the system, leading to a different aerosol loss during transport.
However, the best solution would be to operate at a much lower fraction of aerosol loss, as what was obtained for the aerosol with $2 \mu \mathrm{m}$ median droplet diameter.

The possible configuration and results obtained and described above are based on values that can be used in the industrial-scale process, as shown in Table 1 . Note that all values shown in the table were fixed, which means they only apply to the particular precursor solution, transport system, distributor beam dimensions and temperature, and set of reactions used. The design variables are the number of parallel pipes and their inner diameter, the ultrasonic frequency for the aerosol sizing, the flow rate, and the precursor concentration. However, the models presented can also simulate the process for different precursor solutions, different transport systems, and different chemical reactions, with the aim of serving as a guide to the AACVD scale-up.

\section{CONCLUSION}

The manufacture of coatings and thin films such as the TCOs is often limited by high costs, environmental impacts, and a 


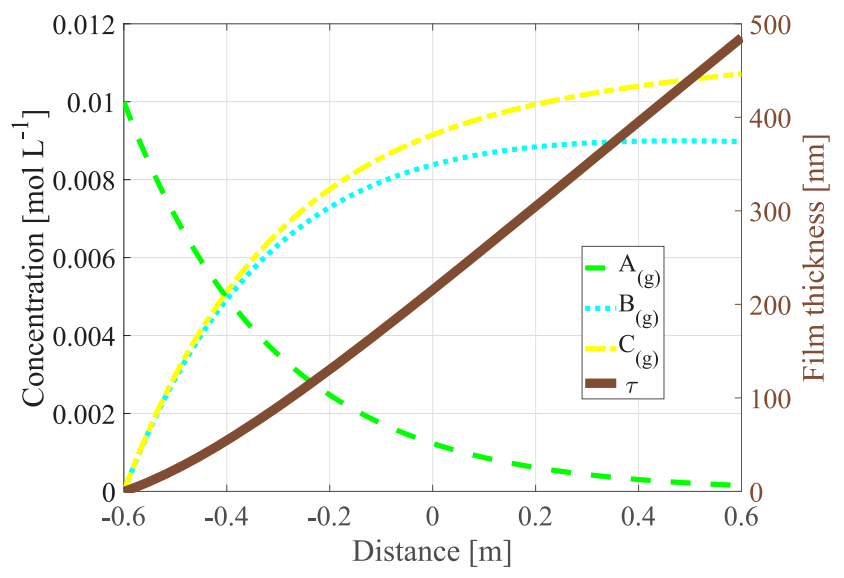

Figure 5. Concentration of the gaseous species in different regions of the deposition site. The reactant A is consumed, while intermediate $\mathrm{B}$ and byproduct $\mathrm{C}$ are produced and the film is grown. The film thickness, $\tau[\mathrm{nm}]$, is shown in the secondary axis. These results are for the parallel flow setting and are equivalent to results in Figure $4 b$.

scarcity of specific precursors. Therefore, it is essential to look for less expensive and more sustainable processes, which becomes an easier task as AACVD enables the consideration of a wider range of precursors. The models presented for the aerosol generation, aerosol transport, aerosol delivery, and chemical deposition, along with the preliminary simulations, worked as a proof of concept for the use of simulation for gaining insights into the feasibility of an industrial-scale AACVD process and the possibility of keeping the current CVD equipment used in the industry to operate the AACVD technique instead.

The models are suitable for the application to process scaleup. They can also be used for different ranges of the variables and parameters studied and should be suitable for applications that rely on the atomization and transport of particles, for example, spray drying or cooling, inkjet printing, agricultural sprays, and fuel combustion, as well as in chemical deposition processes. Furthermore, the lessons learned in modeling uncertainties and their impact on a process scale-up motivates research into formulation, modeling, and solution methods for such applications. The aim is to ease the procedure of design under uncertainty for a process scale-up and facilitate the interactions between different professionals, such as chemists and engineers. Future work will include further model validation and the integration of the models within an optimization-based design framework. The use of a design framework would enable the identification of the best settings for the design variables for specific film growth rates and optoelectronic film properties. The lumped nature of the models presented also possible make the consideration of their use within a real-time optimization system, possibly enabling a more robust or flexible operation.

\section{ASSOCIATED CONTENT}

\section{SI Supporting Information}

The Supporting Information is available free of charge at https://pubs.acs.org/doi/10.1021/acs.iecr.9b05869.

Correlations used to estimate parameters for the aerosol transport and delivery models and figures of schematics (PDF)

\section{AUTHOR INFORMATION}

\section{Corresponding Author}

Eric S. Fraga - University College London, London, United Kingdom; Phone: +44-020-7679-3817;

Email: e.fraga@ucl.ac.uk

\section{Other Authors}

Pedro I. O. Filho - University College London, London, United Kingdom; (1) orcid.org/0000-0002-1041-4982

Claire J. Carmalt - University College London, London, United Kingdom; orcid.org/0000-0003-1788-6971

Panagiota Angeli - University College London, London, United Kingdom

Complete contact information is available at:

https://pubs.acs.org/10.1021/acs.iecr.9b05869

\section{Notes}

The authors declare no competing financial interest.

\section{ACKNOWLEDGMENTS}

The authors acknowledge the support provided by $\mathrm{CNPq}$ (Conselho Nacional de Desenvolvimento Científico e Tecnológico) and the EPSRC (Engineering and Physical Sciences Research Council) EP/L017709/1. P.I.O.F. appreciates the helpful discussions with Dr. Annabel Cormack.

\section{REFERENCES}

(1) Marchand, P.; Hassan, I. A.; Parkin, I. P.; Carmalt, C. J. AerosolAssisted Delivery of Precursors for Chemical Vapour Deposition: Expanding the Scope of CVD for Materials Fabrication. Dalton Trans. 2013, 42 (26), 9406-9422.

(2) Hou, X.; Choy, K. L. Processing and Applications of AerosolAssisted Chemical Vapor Deposition. Chem. Vap. Deposition 2006, 12, 583-596.

(3) Choy, K. L. Chemical Vapour Deposition of Coatings. Prog. Mater. Sci. 2003, 48 (2), 57-170.

(4) Zhang, Y.; Zhang, L.; Zhou, C. Review of Chemical Vapor Deposition of Graphene and Related Applications. Acc. Chem. Res. 2013, 46, 2329-2339.

(5) Reina, A.; Jia, X.; Ho, J.; Nezich, D.; Son, H.; Bulovic, V.; Dresselhaus, M. S.; Kong, J. Large Area, Few-Layer Graphene Films on Arbitrary Substrates by Chemical Vapor Deposition. Nano Lett. 2009, 9, 30-35.

(6) Reddy, A. L. M.; Srivastava, A.; Gowda, S. R.; Gullapalli, H.; Dubey, M.; Ajayan, P. M. Synthesis Of Nitrogen-Doped Graphene Films for Lithium Battery Application. ACS Nano 2010, 4, 63376342 .

(7) Park, S.; Vosguerichian, M.; Bao, Z. A Review of Fabrication and Applications of Carbon Nanotube Film-Based Flexible Electronics. Nanoscale 2013, 5 (5), 1727-1752.

(8) Wu, Y.; Lin, Y.; Bol, A. A.; Jenkins, K. A.; Xia, F.; Farmer, D. B.; Zhu, Y.; Avouris, P. High-Frequency, Scaled Graphene Transistors on Diamond-Like Carbon. Nature 2011, 472, 74-78.

(9) Chung, C.; Kim, Y.-K.; Shin, D.; Ryoo, S.-R.; Hong, B. H.; Min, D.-H. Biomedical Applications of Graphene and Graphene Oxide. Acc. Chem. Res. 2013, 46, 2211-2224.

(10) Sinha, N.; Ma, J. Z.; Yeow, J. T. W. Carbon Nanotube-Based Sensors. J. Nanosci. Nanotechnol. 2006, 6, 573-590.

(11) Li, X.-M.; Reinhoudt, D.; Crego-Calama, M. What Do We Need for a Superhydrophobic Surface? A Review on the Recent Progress in the Preparation of Superhydrophobic Surfaces. Chem. Soc. Rev. 2007, 36 (8), 1350-1368.

(12) Crick, C. R.; Parkin, I. P. Preparation and Characterisation of Super-Hydrophobic Surfaces. Chem. - Eur. J. 2010, 16 (12), 35683588. 
(13) Mellott, N. P.; Durucan, C.; Pantano, C. G.; Guglielmi, M. Commercial and Laboratory Prepared Titanium Dioxide Thin Films for Self-Cleaning Glasses: Photocatalytic Performance and Chemical Durability. Thin Solid Films 2006, 502, 112-120.

(14) Zhang, L.; Xue, C.-H.; Cao, M.; Zhang, M.-M.; Li, M.; Ma, J.-Z. Highly Transparent Fluorine Free Superhydrophobic Silica Nanotube Coating. Chem. Eng. J. 2017, 320, 244-252.

(15) Chopra, K. L.; Paulson, P. D.; Dutta, V. Thin-Film Solar Cells: an Overview. Prog. Photovoltaics 2004, 12, 69-92.

(16) Sajan, C. P.; Wageh, S.; Al-Ghamdi, A. A.; Yu, J.; Cao, S. $\mathrm{TiO}_{2}$ Nanosheets with Exposed $\{001\}$ Facets for Photocatalytic Applications. Nano Res. 2016, 9, 3-27.

(17) Franklin, E.; Fong, K.; McIntosh, K.; Fell, A.; Blakers, A.; Kho, T.; Walter, D.; Wang, D.; Zin, N.; Stocks, M.; Wang, E.-C.; Grant, N.; Wan, Y.; Yang, Y.; Zhang, X.; Feng, Z.; Verlinden, P. J. Design, Fabrication and Characterisation of a $24.4 \%$ Efficient Interdigitated Back Contact Solar Cell. Prog. Photovoltaics 2016, 24, 411-427.

(18) Jiang, Y.; Leyden, M. R.; Qiu, L.; Wang, S.; Ono, L. K.; Wu, Z.; Juarez-Perez, E. J.; Qi, Y. Combination of Hybrid CVD and Cation Exchange for Upscaling Cs-Substituted Mixed Cation Perovskite Solar Cells with High Efficiency and Stability. Adv. Funct. Mater. 2018, 28, $1-13$.

(19) Potter, D. B.; Parkin, I. P.; Carmalt, C. J. The Effect of Solvent on Al-Doped $\mathrm{ZnO}$ Thin Films Deposited via Aerosol-Assisted CVD. RSC Adv. 2018, 8 (58), 33164-33173.

(20) Zhang, J.; Wang, L.; Liu, X.; Li, X.; Huang, W. HighPerformance CdS-ZnS Core-Shell Nanorod Array Photoelectrode for Photoelectrochemical Hydrogen Generation. J. Mater. Chem. A 2015, 3, 535-541.

(21) Sathasivam, S.; Bhachu, D. S.; Lu, Y.; Chadwick, N.; Althabaiti, S. A.; Alyoubi, A. O.; Basahel, S. N.; Carmalt, C. J.; Parkin, I. P. Tungsten Doped $\mathrm{TiO}_{2}$ with Enhanced Photocatalytic and Optoelectrical Properties via Aerosol Assisted Chemical Vapor Deposition. Sci. Rep. 2015, 5, 1-10.

(22) Bhachu, D. S.; Scanlon, D. O.; Saban, E. J.; Bronstein, H.; Parkin, I. P.; Carmalt, C. J.; Palgrave, R. G. Scalable Route to $\mathrm{CH}_{3} \mathrm{NH}_{3} \mathrm{PbI}_{3}$ Perovskite Thin Films by Aerosol Assisted Chemical Vapour Deposition. J. Mater. Chem. A 2015, 3 (17), 9071-9073.

(23) Knapp, C. E.; Hyett, G.; Parkin, I. P.; Carmalt, C. J. AerosolAssisted Chemical Vapor Deposition of Transparent Conductive Gallium-Indium-Oxide Films. Chem. Mater. 2011, 23, 1719-1726.

(24) Potter, D. B.; Bhachu, D. S.; Powell, M. J.; Darr, J. A.; Parkin, I. P.; Carmalt, C. J. Al-, Ga-, and In-Doped ZnO Thin Films via Aerosol Assisted CVD for Use as Transparent Conducting Oxides. Phys. Status Solidi A 2016, 213, 1346-1352.

(25) Tombesi, A.; Li, S.; Sathasivam, S.; Page, K.; Heale, F. L.; Pettinari, C.; Carmalt, C. J.; Parkin, I. P. Aerosol-Assisted Chemical Vapour Deposition of Transparent Superhydrophobic Film by Using Mixed Functional Alkoxysilanes. Sci. Rep. 2019, 9, 1-12.

(26) Potter, D. B.; Powell, M. J.; Darr, J. A.; Parkin, I. P.; Carmalt, C. J. Transparent Conducting Oxide Thin Films of Si-Doped $\mathrm{ZnO}$ Prepared by Aerosol Assisted CVD. RSC Adv. 2017, 7 (18), 1080610814.

(27) Zhuang, A.; Liao, R.; Dixon, S. C.; Lu, Y.; Sathasivam, S.; Parkin, I. P.; Carmalt, C. J. Transparent Superhydrophobic PTFE Films via One-Step Aerosol Assisted Chemical Vapor Deposition. RSC Adv. 2017, 7 (47), 29275-29283.

(28) Powell, M. J.; Potter, D. B.; Wilson, R. L.; Darr, J. A.; Parkin, I. P.; Carmalt, C. J. Scaling Aerosol Assisted Chemical Vapour Deposition: Exploring the Relationship Between Growth Rate and Film Properties. Mater. Des. 2017, 129, 116-124.

(29) Potter, D. B.; Powell, M. J.; Parkin, I. P.; Carmalt, C. J. Aluminium/Gallium, Indium/Gallium, and Aluminium/Indium CoDoped $\mathrm{ZnO}$ Thin Films Deposited via Aerosol Assisted CVD. J. Mater. Chem. C 2018, 6 (3), 588-597.

(30) Blackburn, B.; Hassan, I.; Zhang, C.; Blackman, C.; Holt, K.; Carmalt, C. J. Aerosol Assisted Chemical Vapour Deposition Synthesis of Copper(I) Oxide Thin Films for $\mathrm{CO}_{2}$ Reduction Photocatalysis. J. Nanosci. Nanotechnol. 2016, 16 (9), 10112-10116.
(31) Powell, M. J.; Williamson, B. A. D.; Baek, S.-Y.; Manzi, J.; Potter, D. B.; Scanlon, D. O.; Carmalt, C. J. Phosphorus Doped $\mathrm{SnO}_{2}$ Thin Films for Transparent Conducting Oxide Applications: Synthesis, Optoelectronic Properties and Computational Models. Chem. Sci. 2018, 9 (41), 7968-7980.

(32) Ling, M.; Blackman, C. S.; Palgrave, R. G.; Sotelo-Vazquez, C.; Kafizas, A.; Parkin, I. P. Correlation of Optical Properties, Electronic Structure, and Photocatalytic Activity in Nanostructured Tungsten Oxide. Adv. Mater. Interfaces 2017, 4, 1-7.

(33) Francois, G.; Bonvin, D. Measurement-Based Real-Time Optimization of Chemical Processes. Control and Optimisation of Process Systems; Academic Press: Cambridge, Massachusetts, 2013; pp $1-50$.

(34) Malhotra, G. Scale-up to Commercialization. Chemical Process Simplification; John Wiley \& Sons: New York, 2011; pp 171-188.

(35) Singh, U. K.; Reizman, B. J.; Changi, S. M.; Burt, J. L.; Orella, C. Reaction Kinetics and Characterization. In Chemical Engineering in the Pharmaceutical Industry; John Wiley \& Sons: New York, 2019; pp $151-190$.

(36) Zlokarnik, M. Scale-Up of Chemical and Biotechnological Processes. Encyclopedia of Industrial Biotechnology; John Wiley \& Sons: New York, 2010; pp 1-24.

(37) Moran, S.; Zlokarnik, M. Scale-Up in Chemical Engineering. Ullmann's Encyclopedia of Industrial Chemistry; American Cancer Society: New York, 2010; pp 1-24.

(38) Yang, H.; Allen, D. G. Model-Based Scale-up Strategy for Mycelial Fermentation Processes. Can. J. Chem. Eng. 1999, 77 (5), 844-854.

(39) Grossmann, I. E.; Apap, R. M.; Calfa, B. A.; García-Herreros, P.; Zhang, Q. Recent Advances in Mathematical Programming Techniques for the Optimization of Process Systems under Uncertainty. Comput. Chem. Eng. 2016, 91, 3-14.

(40) Iooss, B.; Saltelli, A. Introduction to Sensitivity Analysis. In Handbook of Uncertainty Quantification; Ghanem, R., Higdon, D., Owhadi, H., Eds.; Springer International Publishing: New York, 2017; pp 1103-1122.

(41) Filho, P. I. O.; Potter, D. B.; Powell, M. J.; Carmalt, C. J.; Angeli, P.; Fraga, E. S. Probability Density Functions for Droplet Sizing in Aerosol Transport Modelling. Comput.-Aided Chem. Eng. 2017, 40 (1), 2245-2250.

(42) Filho, P. I. O.; Angeli, P.; Fraga, E. S. Modelling under Uncertainty for Process Design and Scale-up of an Industrial AACVD. Comput.-Aided Chem. Eng. 2018, 44 (1), 253-258.

(43) Finetti, B. Theory of Probability: A critical introductory treatment; Wiley-Blackwell: New Jersey, 2017.

(44) Dobry, D. E.; Settell, D. M.; Baumann, J. M. Spray Drying and Scale-Up. Pharmaceutical Sciences Encyclopedia; American Cancer Society: New York, 2015; pp 1-26.

(45) Hannon, J. Characterization and First Principles Prediction of API Unit Operations. Chemical Engineering in the Pharmaceutical Industry; John Wiley \& Sons: New York, 2019; pp 203-226.

(46) Mezhericher, M.; Levy, A.; Borde, I. Modelling of Particle Breakage During Drying. Chem. Eng. Process. 2008, 47, 1404-1411.

(47) Bergman, T. L.; Lavine, A. S.; Incropera, F. P.; DeWitt, D. P. Fundamentals of Heat and Mass Transfer; John Wiley \& Sons: New York, 2011.

(48) Christodoulou, C.; Sorensen, E.; García-Muñoz, S.; Mazzei, L. Mathematical Modelling of Water Absorption and Evaporation in a Pharmaceutical Tablet During Film Coating. Chem. Eng. Sci. 2018, $175,40-55$.

(49) Green, D.; Southard, M. Z. Perry's Chemical Engineers' Handbook; McGraw-Hill Education: New York, 2018.

(50) Grossmann, I. E. Evolution of Process Systems Engineering and Future Trends in Research. Comput.-Aided Chem. Eng. 2017, 40, 1-2.

(51) Grossmann, I. E.; Westerberg, A. W. Research Challenges in Process Systems Engineering. AIChE J. 2000, 46, 1700-1703.

(52) Filho, P. I. O.; Fraga, E. S. On the Design and Implementation of a Process Modelling Language for Uncertainty. Comput.-Aided Chem. Eng. 2019, 46 (1), 895-890. 
(53) Rajan, R.; Pandit, A. B. Correlations to Predict Droplet Size in Ultrasonic Atomisation. Ultrasonics 2001, 39, 235-255.

(54) Ramachandran, G.; Cooper, D. W. Size Distribution Data Analysis and Presentation. In Aerosol Measurement; Kulkarni, P., Baron, P. A., Willeke, K., Eds.; John Wiley \& Sons: New York, 2011; pp 479-506.

(55) Yasuda, K.; Bando, Y.; Yamaguchi, S.; Nakamura, M.; Oda, A.; Kawase, Y. Analysis of Concentration Characteristics in Ultrasonic Atomization by Droplet Diameter Distribution. Ultrason. Sonochem. 2005, 12, 37-41.

(56) Lang, R. Ultrasonic Atomization of Liquids. J. Acoust. Soc. Am. 1962, 34 (1), 6-8.

(57) Bang, J. H.; Suslick, K. S. Applications of Ultrasound to the Synthesis of Nanostructured Materials. Adv. Mater. 2010, 22 (10), 1039-1059.

(58) Anand, N.; Mcfarland, A.; Kihm, K.; Wong, F. Optimization of Aerosol Penetration Through Transport Lines. Aerosol Sci. Technol. 1992, 16, 105-112.

(59) Liu, D.-L. Particle Deposition onto Enclosure Surfaces. In Developments in Surface Contamination and Cleaning; Kohli, R., Mittal, K. L., Eds.; William Andrew Publishing: Oxford, 2010; pp 1-56.

(60) Brockmann, J. E. Aerosol Transport in Sampling Lines and Inlets. In Aerosol Measurement; Kulkarni, P., Baron, P. A., Willeke, K., Eds.; John Wiley \& Sons: New York, 2011; pp 68-105.

(61) Mcfarland, A.; Wong, F.; Anand, N.; Ortiz, C. Aerosol Penetration Through a Model Transport-System - Comparison of Theory and Experiment. Environ. Sci. Technol. 1991, 25, 1573-1577.

(62) Cheng, Y.; Wang, C. Motion of Particles in Bends of Circular Pipes. Atmos. Environ. 1981, 15 (3), 301-306.

(63) Pilou, M.; Tsangaris, S.; Neofytou, P.; Housiadas, C.; Drossinos, Y. Inertial Particle Deposition in a 90 Degrees Laminar Flow Bend: An Eulerian Fluid Particle Approach. Aerosol Sci. Technol. 2011, 45 (11), 1376-1387.

(64) Wilson, S. R.; Liu, Y.; Matida, E. A.; Johnson, M. R. Aerosol Deposition Measurements as a Function of Reynolds Number for Turbulent Flow in a Ninety-Degree Pipe Bend. Aerosol Sci. Technol. 2011, 45 (3), 364-375.

(65) Wang, Z.-J.; Ding, F.; Eres, G.; Antonietti, M.; Schloegl, R.; Willinger, M. G. Formation Mechanism, Growth Kinetics, and Stability Limits of Graphene Adlayers in Metal-Catalyzed CVD Growth. Adv. Mater. Interfaces 2018, 5 (14), 1-15.

(66) Wu, T.; Zhang, X.; Yuan, Q.; Xue, J.; Lu, G.; Liu, Z.; Wang, H.; Wang, H.; Ding, F.; Yu, Q.; Xie, X.; Jiang, M. Fast Growth of InchSized Single-Crystalline Graphene from a Controlled Single Nucleus on $\mathrm{Cu}-\mathrm{Ni}$ Alloys. Nat. Mater. 2016, 15, 43-47.

(67) Cai, Z.; Liu, B.; Zou, X.; Cheng, H.-M. Chemical Vapor Deposition Growth and Applications of Two-Dimensional Materials and Their Heterostructures. Chem. Rev. 2018, 118, 6091-6133.

(68) Li, X.; Colombo, L.; Ruoff, R. S. Synthesis of Graphene Films on Copper Foils by Chemical Vapor Deposition. Adv. Mater. 2016, 28 (29), 6247-6252.

(69) Liu, B.; Fathi, M.; Chen, L.; Abbas, A.; Ma, Y.; Zhou, C. Chemical Vapor Deposition Growth of Monolayer WSe2 with Tunable Device Characteristics and Growth Mechanism Study. ACS Nano 2015, 9, 6119-6127.

(70) Hafeez, M.; Gan, L.; Li, H.; Ma, Y.; Zhai, T. Large-Area Bilayer $\mathrm{ReS}_{2}$ Film/Multilayer $\mathrm{ReS}_{2}$ Flakes Synthesized by Chemical Vapor Deposition for High Performance Photodetectors. Adv. Funct. Mater. 2016, 26, 4551-4560.

(71) He, X.; Liu, F.; Hu, P.; Fu, W.; Wang, X.; Zeng, Q.; Zhao, W.; Liu, Z. Chemical Vapor Deposition of High-Quality and Atomically Layered $\mathrm{ReS}_{2}$. Small 2015, 11 (40), 5423-5429.

(72) Wang, Z.-J.; Weinberg, G.; Zhang, Q.; Lunkenbein, T.; KleinHoffmann, A.; Kurnatowska, M.; Plodinec, M.; Li, Q.; Chi, L.; Schloegl, R.; Willinger, M.-G. Direct Observation of Graphene Growth and Associated Copper Substrate Dynamics by in Situ Scanning Electron Microscopy. ACS Nano 2015, 9, 1506-1519.
(73) Lu, G.; Wu, T.; Yuan, Q.; Wang, H.; Wang, H.; Ding, F.; Xie, $\mathrm{X}$.; Jiang, M. Synthesis of Large Single-Crystal Hexagonal Boron Nitride Grains on Cu-Ni Alloy. Nat. Commun. 2015, 6, 1-7.

(74) Yan, A.; Velasco, J.; Kahn, S.; Watanabe, K.; Taniguchi, T.; Wang, F.; Crommie, M. F.; Zettl, A. Direct Growth of Single- and Few-Layer $\mathrm{MoS}_{2}$ on h-BN with Preferred Relative Rotation Angles. Nano Lett. 2015, 15, 6324-6331.

(75) Li, H.; Li, Y.; Aljarb, A.; Shi, Y.; Li, L.-J. Epitaxial Growth of Two-Dimensional Layered Transition-Metal Dichalcogenides: Growth Mechanism, Controllability, and Scalability. Chem. Rev. 2018, 118, 6134-6150.

(76) Zheng, B.; Chen, Y.; Wang, Z.; Qi, F.; Huang, Z.; Hao, X.; Li, P.; Zhang, W.; Li, Y. Vertically Oriented Few-Layered $\mathrm{HfS}_{2}$ Nanosheets: Growth Mechanism and Optical Properties. 2D Mater. 2016, 3, 1-9.

(77) Wang, S.; Liu, M.; Kong, L.; Long, Y.; Jiang, X.; Yu, A. Recent Progress in $\mathrm{VO}_{2}$ Smart Coatings: Strategies to Improve the Thermochromic Properties. Prog. Mater. Sci. 2016, 81, 1-54.

(78) Rahman, M.; Davey, K.; Qiao, S.-Z. Advent of 2D Rhenium Disulfide $\left(\operatorname{ReS}_{2}\right)$ : Fundamentals to Applications. Adv. Funct. Mater. 2017, 27, 1-21.

(79) Li, X.-G.; Xiao, W.-D. Silane Pyrolysis to Silicon Rod in a BellJar Reactor at High Temperature and Pressure: Modeling and Simulation. Ind. Eng. Chem. Res. 2016, 55, 4887-4896.

(80) Cavallotti, C.; Rossi, F.; Ravasio, S.; Masi, M. A Kinetic Analysis of the Growth and Doping Kinetics of the SiC Chemical Vapor Deposition Process. Ind. Eng. Chem. Res. 2014, 53, 9076-9087. (81) Salinger, A. G.; Pawlowski, R. P.; Shadid, J. N.; Waanders, B. G. Computational Analysis and Optimization of a Chemical Vapor Deposition Reactor with Large-Scale Computing. Ind. Eng. Chem. Res. 2004, 43, 4612-4623.

(82) Wang, H.; Stern, H. A. G.; Chakraborty, D.; Bai, H.; DiFilippo, V.; Goela, J. S.; Pickering, M. A.; Gale, J. D. Computational Study of Surface Deposition and Gas Phase Powder Formation during Spinel Chemical Vapor Deposition Processes. Ind. Eng. Chem. Res. 2013, 52, $15270-15280$.

(83) Samandari-Masouleh, L.; Mostoufi, N.; Khodadadi, A.; Mortazavi, Y.; Maghrebi, M. Modeling the Growth of Carbon Nanotubes in a Floating Catalyst Reactor. Ind. Eng. Chem. Res. 2012, $51,1143-1149$

(84) Vallerio, M.; Telen, D.; Cabianca, L.; Manenti, F.; Impe, J.; Logist, F. Robust Multiobjective Dynamic Optimization of Chemical Processes Using the Sigma Point Method. Chem. Eng. Sci. 2016, 140, 201-216.

(85) Achenie, L. E. K.; Sharifi, Y.; Lee, D. G. Development of a Multiscale Strategy and Application to Chemical Vapor Deposition. Tools For Chemical Product Design: From Consumer Products to Biomedicine; Elsevier, 2016; pp 95-124.

(86) Powell, M. J.; Carmalt, C. J. Aerosols: A Sustainable Route to Functional Materials. Chem. - Eur. J. 2017, 23 (62), 15543-15552.

(87) Knapp, C. E.; Dyer, C.; Chadwick, N. P.; Hazael, R.; Carmalt, C. J. Metal $\beta$-Diketoiminate Precursor Use in Aerosol Assisted Chemical Vapour Deposition of Gallium- and Aluminium-Doped Zinc Oxide. Polyhedron 2018, 140, 35-41.

(88) Soubeyrand, M. J. Glass Coating Method and Glass Coated Thereby. World Intellectual Property Organization Patent WO199601180 A1.

\section{NOTE ADDED AFTER ASAP PUBLICATION}

This paper was published ASAP on January 10, 2020, with an incorrect spelling in the Acknowledgments. The corrected version was reposted on January 13, 2020. 